\title{
Effects of polyphenol (carob) supplementation on body composition and aerobic capacity in taekwondo athletes
}

Nawel Gaamouri ${ }^{1,2}$, Hassane Zouhal ${ }^{3}$, Mehrez Hammami ${ }^{1,2}$, Anthony C. Hackney ${ }^{4}$, Abderraouf Ben Abderrahman ${ }^{2}$, Ayoub Saeidi ${ }^{5}$, Omar Ben Ounis ${ }^{2}$

${ }^{1}$ Research Unit (UR17JS01) «Sport Performance, Health \& Society», Higher Institute of Sport and Physical Education of Ksar Saîd, University of "La Manouba”, Tunis, Tunisia.

${ }^{4}$ Higher Institute of Sport and Physical Education of Ksar Said, University of "La Manouba", Tunis, Tunisia.

${ }^{3}$ University Rennes, M2S (Laboratoire Mouvement, Sport, Santé) - EA 1274, F-35000 Rennes, France.

${ }^{4}$ Endocrine Section - Department of Exercise \& Sport Science, University of North Carolina, Chapel Hill, NC, United States.

${ }^{5}$ Exercise Biochemistry Division, Faculty of Physical Education and Sport Science, University of Mazandaran, Babolsar, Iran

*Corresponding author: Prof. H. ZOUHAL, PhD.

University Rennes, M2S (Laboratoire Mouvement, Sport, Santé) - EA 1274, F-35000 Rennes, France.

hassane.zouhal@univ-rennes2.fr 


\begin{abstract}
Herbal products and supplements use by athletes has increased over the past decade. One such item being polyphenols. These are reported to reduce weight and modify body composition, which could aid athletes in many sports. Therefore, the purpose of the study was to determine the effect of 6 weeks supplementation with carob, a naturally occurring polyphenol, on body composition and aerobic capacity in youth taekwondo athletes. Twenty-three taekwondo athletes $\left(21.9 \pm 1.2\right.$ years; $1.64 \pm 0.03 \mathrm{~m} ; 67.4 \pm 17.3 \mathrm{~kg}$;BMI: $22.8 \pm 5.5 \mathrm{~kg} / \mathrm{m}^{2}$ ) participated in a short-term (6-week) double-blind randomized design parallel fully controlled training study (pre-to-post measurements): Supplemented group (SG), $\mathrm{n}=11$;placebo group (PG), $\mathrm{n}=12$. Body composition, aerobic capacity, heart rate and RPE were analyzed before and after 6weeks of carob rich polyphenol ingestion. Significantly greater decreases in weight were observed for SG and PG (-2.82\% and $-0.51 \%$ respectively) with differences between groups $(\mathrm{p}<0.001)$. No significant differences were reported in percentage body fat and muscular volume between groups. Our results revealed an improvement of aerobic performance score and RPE with differences between groups. A cute polyphenol supplementation seemed to be effective in reducing body weight and improving aerobic performance in athletes.
\end{abstract}

Key words: polyphenol supplementation; anthropometry; endurance; martial arts; body weight 


\section{Introduction}

Nowadays, sports are highly competitive and can be financially lucrative [1]. Thus, coaches and athletes are continuously looking for ways to raise the level of athletic performance in order to achieve sporting success [2].Taekwondo (TKD) is an Olympic category-weight martial art practiced in over 180 countries worldwide [3]. Performance in TKD is related to technical and select physical fitness components [4, 5]. Among the physical fitness components - anthropometry, aerobic fitness sand neuromuscular function have been identified as important determinants of performance [6, 7]and are evaluated routinely in athletes [8]. Relative to anthropometric characteristics, body height, body mass, body mass index (BMI), and body fat percentage (BF) have been shown to be critical $[9,10]$. Furthermore, a significant proportion of TKD athletes regularly reduce their body mass to compete in their selected weight divisions $[11,12]$.

In this context, it is common for these athletes used a variety of dietary supplements from both natural and organic sources, in order to increase energy levels, maintain strength, health and immune system function, enhance performance, and prevent nutritional deficiencies which compromise health [13]. As well as, not violate doping regulations in using other nonnatural or organic agents.

Experts now divide supplements into categories such as; traditional, less traditional and nontraditional supplements [14]. Those supplements typically contain chemical compounds extracted from fruit and vegetables, leaves, pods, roots and seeds. The idea being that chemical compounds in fruit and vegetables, other than the vitamins and minerals, may have health benefits [15].

Polyphenols are vastly diverse phytochemicals with complex chemical structures. They are found in a variety of commonly consumed foods such as chocolate, tea, coffee, wine, olive, dry legumes, some vegetables (e.g., lettuce and cabbage) and fruits (e.g., apples and berries) 
[16-18]. Most recently, polyphenols have attracted media and research community interest because of their potential role in reducing obesity, an increasingly serious world-wide health issue affecting all ages [19, 20]. Specific polyphenols such as catechins, anthocyanins, curcumin, and resveratrol have been suggested to exert beneficial effects on lipid and energy metabolism [21] and thus potentially could impact on an individual's weight status.

Intake of dietary polyphenols is reported to enhance whole body antioxidant capacity [22], as well as modulates endothelial function [23]. Polyphenols from various sources have also been shown to have anti-inflammatory properties in patients with coronary heart disease [24].In particular along these lines, the carob fruit, which is a slow-growth evergreen tree, cultivated for years in Mediterranean countries has attracted the interest of researchers [25] as the carob extract is proposed to have antioxidant property; i.e., reported in both in vivo and in vitro studies [26, 27]. For example, Papagiannopoulos et al. [28]identified the chemical composition of carob and it contain many bioactive substances such as carbohydrate, dietary fiber, tannins, and polyphenols [28].Due to its chemical composition, the carob is used in both the food industry and in medicine. In many Arab countries, this fruit is used to make a drink and also used in preparation of traditional types of confectionary. Carob powder is sold in USA and other Western countries in health food stores as a substitute or extender for cocoa. Furthermore, it was recently discovered that leaf carob extract presents some ameliorative effects against alcohol or CCl4-induced oxidative damage in rats' tissues [29, 30].

These effects on energy metabolism and anti-oxidant properties of polyphenols, such as carob, could be of interest to athletes to improve their training; that is, ergogenic effects. Yet the effects of carob have not been extensively studied in the field of sport nutrition and performance enhancement. 
Moreover, as noted, TKD is a weight category sport which performance may be determined by a competitor's technical, tactical, psychological, physical and physiological characteristics [31]. In championship contests, competitors perform brief periods of intensive, fighting activity [i.e., attacks] (1-5 s) interposed with longer periods of non-fighting activity [pause] at average ratios between $1: 2$ and 1:7 in different TKD styles [32, 33]. These contests elicit near maximal heart rate (HR) responses ([90\% HRpeak) and high lactate concentrations (7.0-12.2 mmol. $\left.\mathrm{L}^{-1}\right)$. These findings support the fact that great demands are placed upon both upon both the anaerobic compared to the aerobic during TKD matches [32, 34, 35]. Obviously, the aerobic metabolism, becomes essential in the intervals of rounds, or even in a combat, when athletes perform more than once during a competition day, and to aid the recovery process,

Since polyphenols supplements are not banned by the World Anti-doping Agency (WADA) and known to have positive effects on body composition and overall health, the aim of this study was to examine whether 6 weeks' daily consumption of this carob would affect aerobic performance and improve body composition in TKD athletes.

\section{Methods}

\subsection{Participants}

The participants (age 21.91 \pm 1.22 years; weight $1.64 \pm 0.03 \mathrm{~m}$; height $67.34 \pm 17.26 \mathrm{~kg}$; BMI: $22.77 \pm 5.54 \mathrm{~kg} / \mathrm{m}^{2}$ ) were recruited based on the following criteria: (i) they trained at least three sessions per week of 90 to $120 \mathrm{~min}$ duration per session; (ii) they had an performance experience of more than three years at National level; and, (iii) they did not have any injuries and they did not currently use any antioxidant (e.g., vitamin E, A, C etc.) or anti-inflammatory drugs during the experimental period and one month before. Prior to commencing the study, all subjects were informed about the experimental procedures and the possible risks and 
discomforts associated with the study and each signed a written informed consent prior to participation. All procedures were approved by the University Institutional Review Committee for the ethical use of human subjects, according to current national, international laws, and regulations.

To assess the adequacy of nutrient intake, participants completed a consecutive dietary record over 7 days prior to the study. All participants received a detailed verbal explanation and written instructions on data collection procedures. Participants were asked to continue with their usual dietary habits during the period of dietary recording and to be as accurate as possible in recording the amounts and types of food and fluid consumed. A list of common household measures, such as cups and tablespoons, and specific information about the quantity in each measurement (e.g., grams) were given to each participant. Each individual's diet was calculated using the Bilnut 4 software package (SCDA Nutrisoft, Cerelles, France) and the food composition tables published by the Tunisian National Institute of Statistics. Estimated nutrient intakes were referred to reference dietary intakes for physically active people and the daily nutriment data showed that total calorie, macronutrient, and micronutrient intakes are situated in the interval of the reference dietary intakes for healthy Tunisian adults.

\subsection{Experimental overview}

A double-blind randomized design was utilized to examine whether 6 weeks of polyphenol supplementation would enhance body composition and aerobic performance in taekwondo athletes who maintained their customary in-season training regimen. A group of 23 taekwondo athletes volunteered for random, blind assignment to either a supplemented group $(\mathrm{SG} ; \mathrm{n}=11,5$ women and 6 males) or a placebo group (PG; $\mathrm{n}=12,6$ women and 6 males). The participants completed two familiarization trials for 2-weeks before research testing began; data were collected immediately before the start of the training period and after 
completion of the 6-week trial. On each testing occasion, the protocol included anthropometric measurements and a "yo-yo" test with measurement of heart rate and rating of perceived exertion (RPE) scores. Testing sessions were carried out at the same time of the day and under the same experimental conditions.

\subsection{Experimental Treatment}

All of the athletes followed the same training sessions during the experience period. Thus, the intensity of exercises was similar within the two groups (supplemented and Placebo). The training program included specific technical interval training (IT) [36], tactical technical training sessions (TT), technical-development training sessions and free TKD sparring. The aerobic interval training within their program consisted of four bouts of exercise lasting for 4 minutes with 4 minutes of active recovery in-between (Table 1).

The ratio1: 1 (i.e., $4 \mathrm{~min}: 4 \mathrm{~min}$ ) allowed us to implement the sparing. Each bout consisted of short duration high intensity interval exercise (i.e. 10:20 [10 s of exercise interspersed with 20 $\mathrm{s}$ of passive recovery]). During specific TKD training, Bandal Chagui or roundhouse kick techniques were used [37]. The roundhouse kick, a multi-planar skill, starts with the kicking leg traveling in an arc towards the front with the knee in a chambered position. The knee is extended in a snapping movement, striking the opponent with the metatarsal part of the foot extended. Following the warm-up, each athlete performed maximum repeated kicks (i.e., Bandal Chagui) during $10 \mathrm{~s}$. Verbal encouragements were used to keep $90-95 \%$ of athlete' maximal repeated kicks through the 4 bouts of specific TKD training. TT included a general then a specific warm-up (15 min). Then, each athlete practiced various taekwondo techniques (kicking, punching, striking and blocking) in different tactical sparring situations (offensive and/or defensive) for $45 \mathrm{~min}$. In the offensive situation, athletes must continually attack their partners in the body or in the head. During the defensive situations, athletes can counterattack, riposte and/or block. All these exercises were performed in 2-min effort bouts 
separated by 60 -s passive recovery periods. After every three bouts, however, a 3-min passive recovery period was imposed. TT ended with a 10-min period of free Taekwondo sparring. TD was based on technical Kirougui repetitions. This training modality began with a general 15-min warm-up. Then, eight repetitions of 3-min effort bouts separated by 90 -s passive recovery periods were performed. During technical repetitions, each athlete carried out a variety of TKD techniques (kicking, punching, combination of lower and upper limb) performed in either stationary or variable positions. TD ended with a 10-min period of general stretching. Randori included an individual, free 15-min warm-up period. After the warm-up, seven repetitions of 2-min free TKD sparring bouts separated by 1-min passive recovery periods were performed.

***Table 1 about here ***

\subsection{Anthropometry}

The following anthropometric measurements were performed with appropriate scales: height (accuracy $=0.1 \mathrm{~cm}$; Hotain, UK) and body mass $(0.1 \mathrm{~kg}$; Tanita BF683W, Munich, Germany). The overall percentage of body fat was estimated from the biceps, triceps, subscapular, and supra iliac skinfold measurements, using the equation of Durnin and Womersely for body density [38]:

$$
\% \text { Body fat }=(4.95 /(\text { Density }-4.5)) 100
$$

Where; Density $=1.162-0.063$ (Log sum of 4 skinfolds)

\subsection{The yo-yo intermittent recovery test level-1}

Using the procedures described by Krustrup et al. [39], the YYIRT consisted of 20-m shuttle runs performed at increasing velocities with 10 -s of active recovery for a distance of 5-m until exhaustion. The trial was terminated when the participant twice failed to hit the front line in 
time or he felt unable to make out another shuttle. The total distance covered during the YYIRT was considered as the test score. Heart rate peak (HRpeak) was recorded during the YYIRT using a Polar heart rate monitor (T61-coded, Polar Electro Oy, Kempele, Finland).

\subsection{Rating of Perceived Exertion:}

Rating of perceived exertion (RPE, Borg's 10 scale) modified [40], was also used as a measure of each interval training load. Each athlete's RPE was collected immediately after the completion of each interval training session to ensure that the perceived effort referred to the interval training session only. All the athletes who participated were familiarized with CR10 scale for RPE before the commencement of this study.

\subsection{Carob extract and placebo supplementation:}

Natural mature carob pods were collected from the region of Tabarka (North-west of Tunisia). Briefly, the plant material was later dried in an incubator at $50{ }^{\circ} \mathrm{C}$ during $72 \mathrm{~h}$ and powdered in an electric blender (Moulinex Ovatio2, FR). Powder mixture contains carob pulp (90\%) and seeds $(10 \%)$. No additional chemical products were added to the natural polyphenol extract. Each $40 \mathrm{~g}$ of the tested carob powder contained $208 \mathrm{mg}$ of total polyphenol, $14.4 \mathrm{mg}$ of flavonoids. SG and PG groups were reminded verbally through phone communication to consume at the required times their supplements. The placebo juice consisted of a carobflavored commercial drink contained water, citric acid, natural flavor and natural identical flavor (carob), sweeteners (aspartame $\times 0.3 \mathrm{~g} / \mathrm{l})$, acesulfame $\mathrm{K}(0.16 \mathrm{~g} / \mathrm{l})$ ), stabilizers (Arabic gum) and which did not contain antioxidants, vitamins nor polyphenols.

Specifically, $40 \mathrm{~g}$ of carob powder diluted in $250 \mathrm{ml}$ of water were given to athletes in the morning at breakfast during the 6 weeks of the study. The mixture was prepared fresh every day. The PG took daily $250 \mathrm{ml}$ of the carob-flavored commercial drink at the same time of day. 
In order to prevent bias in our research results, a double-blind randomized design was used. Hence, neither the participants (SG and PG) nor the experimenters knew who received carob supplements or placebo.

\subsection{Determination of total phenols:}

\subsubsection{Extraction:}

A test sample of $2 \mathrm{~g}$ of the degreased vegetable material is macerated in $100 \mathrm{ml}$ of the mixture acetone / water $(70 / 30 \mathrm{v} / \mathrm{v})$ for 24 hours at room temperature. After filtration under vacuum, the acetone / water mixture is evaporated to dryness under reduced pressure to $45^{\circ} \mathrm{C}$. The residue obtained is recovered with $3 \mathrm{ml}$ of pure methanol, for subsequent assays[41].

\subsubsection{Dosage by Folin Ciocalteu method:}

The reaction is based on the reduction of the phoshomolybdic acid of the reagent Folin Ciocalteau (a yellow acid, consisting of acid polyheterocycles containing molybdenum andtungsten), by polyphenols in an alkaline medium [42]. It results in the development of a dark blue color due to the formation of atungsten molybdenum complex measured by spectrophotometer.

\subsubsection{Procedure:}

The polyphenols were assayed by the method of Singleton as reported by Dogyan [43]. The residue obtained after extraction was dissolved in $5 \mathrm{ml}$ of distilled water. Subsequently, 100 $\mu \mathrm{l}$ of this solution was diluted to $3 \mathrm{ml}$ and added to $0.5 \mathrm{ml}$ of Folin Ciocalteu reagent. This was allowed to react for 3 minutes, and then $2 \mathrm{ml}$ of $20 \%$ sodium carbonate was added to the solution, which was vortex and incubated in the dark for 1 hour. Finally, the absorbance of the solution was read at $650 \mathrm{~nm}$ for standards and unknowns, and a standard curve established. 


\subsubsection{Expression of results:}

The total polyphenol content was determined from a linear regression equation produced from the calibration curve and expressed in milligrams equivalent of pyrocatechol per $100 \mathrm{~g}$ of dry matter.

\subsection{Statistical analysis:}

Means \pm standard deviations (SD) were used to describe measurements. The assumption of normality was verified using the Kolmogorov-Smirnov test. Paired simple t-test was used to analyze the effect of training program on body composition, physical performances (yo-yo test), HR and RPE. To analyze the effect of polyphenol supplementation on those measures and because of the slight differences in the initial groups, analysis of covariance (ANCOVA) with the pre-test values as the covariate was used to determine differences between the posttest adjusted means in the groups. The effect size was calculated as partial eta-squared ( $\eta$ p2) for ANCOVA and as Cohen's d for the paired sample t-test to assess the practical significance of the findings. ES was classified according to Cohen's $d$ as follows: $<0.2$ was defined as trivial; $0.2-0.6$ was defined as small; >0.6-1.2 was defined as moderate; >1.2-2.0 was defined as large; > 2.0-4.0 was defined as very large; and >4.0 was defined as extremely large. Statistical analyses were performed using the SPSS software statistical package (SPSS Inc., Chicago, IL, version. 20.0), and statistical significance was set at $\mathrm{P}<0.05$. 


\section{Results:}

All the recruited TKD athletes, from both groups, completed the study according to the previously described study design and methodology. No injuries related to training or testing occurred over the course of the study. During the 6-week intervention period, complianceattendance rates amounted to $94.1 \%$ for SG and $92.5 \%$ for PG.

\subsection{Dietary analysis}

Diet analysis showed that there were no significant differences between the participants before or during the study for nutrients intake.

\subsection{Body composition:}

Changes in body composition in SG, compared to PG condition are presented in Table 2. Before the study intervention no significant differences were observed between the groups. After the intervention, a significant group effect was observed for weight, $(F=23.179$; $\mathrm{p}<0.001)$, and BMI $(\mathrm{F}=24.88 ; \mathrm{p}<0.001 ; \eta \mathrm{p} 2=0.537)$. However, ANCOVA revealed no significant group effects for $\mathrm{BF}(\mathrm{F}=32.55 ; \mathrm{P}>0.05 ; \eta \mathrm{p} 2=0.620)$ and muscular volume (MV) $(\mathrm{F}=1.29 . \mathrm{p}>0.05)$. For the weight the $\mathrm{SG}$ had a significant decrease for the $\mathrm{SG}(-2.82 \%$; $\mathrm{P}=0.001$; Cohen's $\mathrm{d}=0.16)$ vs. $(-0.51 \%$; $\mathrm{P}<0.05$; Cohen's $\mathrm{d}=0.02)$ for the placebo group. The SG had a significantly greater improvement in BMI $(-3.16 \% \%$; $<0.001$; Cohen's $d=0.15)$ than PG $(-0.50 \%$; $\mathrm{P}<0.05$; Cohen's $\mathrm{d}=0.03)$.

There were no significant changes from pre- to posttest in the SG and PG for the MV and in PG for the $\% \mathrm{BF}$.

$* * *$ Table 2 about here $* * *$ 


\subsection{Aerobic Performance}

Measurements of aerobic performance (i.e., total distance covered and maximal aerobic velocity) after using PLA and carob supplementation were presented in Table 3. Before the study intervention no significant differences were observed between the groups. After the intervention, the ANCOVA revealed significant group effects for total distance covered $(\mathrm{F}=14.04 ; \quad \mathrm{P}<0,001 ; \eta \mathrm{p} 2=0.412), \quad$ maximal aerobic velocity $\quad(\mathrm{MAV}$ estimated $)(\mathrm{F}=13.55$; $\mathrm{p}<0.001 ; \eta \mathrm{p} 2=0.404)$ and $\mathrm{RPE}$ scales $(\mathrm{F}=18.09 ; \mathrm{P}<0.000 ; \eta \mathrm{p} 2=0.475)$. However, there is no significant group effect for HRpeak $(\mathrm{F}=1.118 ; \mathrm{P}>0.05)$. Distance and MAV improved significantly in SG more $(92.43 \% ; 12.18 \%$ respectively) than PG $(40.37 \% ; 4.95 \%$ respectively). There were no significant changes from pre- to post-test in the SG and PG for the HRpeak and RPE scores.

$* * *$ Table 3 about here $* * *$

\section{Discussion}

Many researches have report that weight loss by a short-term restricted diet could cause decrease in body mass, but this in turn might lead to the deterioration of exercise capacity. Thus, the aim of this study was to examine whether 6 weeks' daily consumption of carob would affect aerobic performance and improve body composition in TKD athletes.

The primary finding of the current study was that 6 weeks daily consumption of $200 \mathrm{mg}$ of carob extract polyphenol for male and female taekwondo athlete's significantly decreased weight and BMI.

Our findings coincided with those reported by Georgakouli et al. [44] who showed that the consumption of a yoghurt rich of polyphenol components reduced the body weight, BMI and 
waist circumference. Similarly, previous reports approved the important role of polyphenols in the decrease of body weight, BMI, visceral fat and the volume of adipose cells [45], and metabolic balance [46]. Recently, Romain et al. [47], studied the effect of mixed polyphenol rich elements on body composition and well-being. Those authors demonstrated that polyphenol supplementation during 16 weeks succeeded in reducing body weight (1.6\%), rebalanced body composition in term of ration lean mass- fatty mass and "refreshed the spirit and body". Similarly, Benaraba [48] approved that the consumption of green tea for 4 months decreased considerably the BMI and waist circumferences and ameliorated the fatty metabolis $\mathrm{m}$, bone properties and serum markers in obese mice.

Contrastingly, Farhat et al. [49] showed that the efficacy of polyphenols remains low, particularly at low doses. Also, Poulsen et al. [50], reported that the administration of 500mg of resveratol during 4 weeks have no significant effect on body weight, BMI and BF. In a human research, Di Renzo et al. [51], demonstrated that 7 days of cocoa supplementation with $2000 \mathrm{mg}$ of polyphenols reduced waist circumference without affecting overall weight. This result has been reinforced by the study of Pfeuffer et al. [52], who showed no difference in body weight and BMI following $150 \mathrm{mg}$ of quercetin administered for two- 8 week.

All of these studies just noted used only supplementation alone without any exercise training to assess carob effects, unlike the current study [52]. Nonetheless, we also found there were no significant changes in percent of body fat $(p>0.05)$ and lean body mass $(p>0.05)$. These results could, at least in part, be explained by the limited time of the intervention (only 6 weeks), which might not have been sufficient to develop the effects of carob on body fat and/or it could relate to the small number of participants in each group and/or by gender differences since each group included women and men [52]. Although, it must be noted the methods and procedures we use are comparable and align with much of the published research literature. 
The disagreement in the findings from various studies probably reflects differences in methodology (e.g., the dose and period of polyphenol administration). Differences between populations could be also an explanation disparate findings. Nonetheless, to our knowledge, there are only a limited number of human studies, which have focus on association between polyphenol consumption and body composition in humans, especially in athletes[53, 54]. Hence our findings add to this limited available research.

Current knowledge suggests that the potential complementary effect of these polyphenols may act through several mechanisms: 1) suppression of fat absorption from the gut, 2) uptake of glucose by skeletal muscles, 3) suppression of anabolic pathways, 4) stimulation of catabolic pathways in adipose tissues, liver and other tissues, 5) inhibition of angiogenesis in adipose tissues, 6) inhibition of differentiation of pre-adipocytes to adipocytes, 7) stimulation of apoptosis of mature adipocytes, and/or 8) reduction of chronic inflammation associated with adiposity[55]. Further research is necessary to explore these options and reach a definitively identify specific mechanism(s).

Although, many factors could affect the replication to these outcomes to human[56]. Firstly, there are many differences in the metabolism and mechanism of action of polyphenols between animals and humans[57]. Secondly, there is a difference in body weight control between animals and free-living humans. The latter exhibit large differences in daily levels of physical activity and energy balance [58].Third, Etcheverry et al [59], demonstrated the complexity of substituting in vitro studies for human studies relies on the limitations in assessing polyphenol bioavailability in cell studies. In addition, some authors explained those differences by the doses of polyphenols that exert a clear effect on obesity in cells [such as the inhibition of adipogenesis [60, 61]; that is, higher than typical physiological levels [56].

There have been many research study reporting that weight loss by a short-term restricted diet could cause decrease in fat free mass and then this in turn might lead to the deterioration of 
exercise capacity. Nevertheless, our primary findings indicate that 6 weeks of dietary polyphenol supplementation (200 mg/day) significantly affect distance covered and maximal aerobic velocity and RPE in response to the Yo-Yo intermittent recovery test. However, there was no effect of polyphenol supplementation on HRpeak responses following this test.

In this context, Davis et al [62], indicated that the administration of quercetin for 7 days induce an improvement in $\mathrm{VO}_{2 \max }$ in humans during a cycling bout. These authors speculated these results as possibly due to altered mitochondrial biogenesis, reduction of reactive oxygen's species, and/or the psycho-stimulatory of the supplement all of which may delay fatigue. Similarly, it should be noted that resveratol increased exercise capabilities and skeletal muscle endurance in mice[63]. In addition, it was reported that resveratrol ameliorated muscle strength and aerobic endurance in rats [64]. In several studies, researchers demonstrated that resveratrol could induce mitochondrial biogenesis, which has subsequently been shown to enhance endurance capacity $[65,66]$.

Contrastingly, the administration of $150 \mathrm{mg} /$ day of resveratrol administration for four weeks to athletes did not affect performance and muscle function response to low-dose high intensity exercise(3days/week) [67]. Similarly, Voduc et al. [68], did not succeed to demonstrate a positive effect of resveratrol administration on exercise duration and aerobic capacity. Also, Labonté et al. [69], found that acute polyphenol intake in elite athletes had no significant effect on performance in 3-Km Time Trial on an ergocycle. The intake of polyphenol also did not affect perceived exertion. As noted earlier, the disagreement in the findings from various studies probably reflect differences in methodology and or subject characteristics.

As noted in part earlier, some limitations need to be acknowledged in the current study: i) the small number of participants in each group; ii) the duration of the intervention, only 6 weeks; iii) no physiological and biochemical parameters were measured (e.g. oxidative stress 
markers, hormones) to reinforce the findings. To address these limitations, long-term studies involving a large cohort and controlling for diet and exercise are needed in order to confirm the potential effect of polyphenols on body composition and aerobic capacity in athletes.

\section{Conclusions}

Findings from the present study show that carob supplementation combined with exercise training are undoubtedly able to, improve some aspects of aerobic capacities as well as weight loss in taekwondo athletes during 6 weeks of training. Additional researches are needed to study mechanisms behind these improvements and to rectify the discrepancies found in the results of some studies.

\section{Practical applications:}

The current study showed clearly that, including foods containing $40 \mathrm{~g}$ of carob richpolyphenol daily in the diet combined with physical exercise during six-week may facilitate weight loss and help to improve aerobic capacities in athletes. Since the U.S. Food and Drug Administration (FDA) approved carob for use in food, pharmaceutics and cosmetics - and due to its low risk - the current findings may be of great interest for athletes of combative sports and their coaches. Consequently, we recommend that combative sport athletes can include carob rich-polyphenol in their nutrition, especially during the last phases of their training programs just before the competitions when they are attempting to make their specific weight classifications without nutrient intake restriction. 


\section{References:}

[1] Michael J Ormsbee, J. L., Paul J Arciero,. Beetroot juice and exercise performance. Nutrition and Dietary Supplements 2013:27-35.

[2] Elsawy G, A. O., Hamza A. Effect of choline supplementation on rapid weight loss and biochemical variables among female taekwondo and judo athletes. . J Hum Kinet $2014 ;$,77-82.

[3] Fong, S. S., Ng, G. Y. Does Taekwondo training improve physical fitness? Physical therapy in sport : official journal of the Association of Chartered Physiotherapists in Sports Medicine. 2011,12:100-6.

[4] Cular, D., Krstulovic, S., Katic, R., Primorac, D., Vucic, D. Predictors of fitness status on success in Taekwondo. Collegium antropologicum. 2013,37:1267-74.

[5] Buśko, K., Nikolaidis, P. T. Biomechanical characteristics of Taekwondo athletes: kicks and punches vs. laboratory tests. Biomedical Human Kinetics. 2018,10:81-8.

[6] Nikolaidis, P. T., Chtourou, H., Torres-Luque, G., Tasiopoulos, I. G., Heller, J., Padulo, J. Effect of a Six-Week Preparation Period on Acute Physiological Responses to a Simulated Combat in Young National-Level Taekwondo Athletes. Journal of human kinetics. 2015,47:115-25.

[7] Sadowski J, G. D., Miller J, Cieśliński I. . Success factors in elite WTF taekwondo competitors. Arch Budo. . 2012,8:141-6

[8] Ball, N., Nolan, E., Wheeler, K. Anthropometrical, physiological, and tracked power profiles of elite taekwondo athletes 9 weeks before the Olympic competition phase. Journal of strength and conditioning research. 2011,25:2752-63.

[9] Kazemi, M., Waalen, J., Morgan, C., White, A. R. A profile of olympic taekwondo competitors. Journal of sports science \& medicine. 2006,5:114-21.

[10] Markovic, G., Misigoj-Durakovic, M., Trninic, S. Fitness profile of elite Croatian female taekwondo athletes. Collegium antropologicum. 2005,29:93-9.

[11] Brito, C. J., Roas, A. F., Brito, I. S., Marins, J. C., Cordova, C., Franchini, E. Methods of body mass reduction by combat sport athletes. International journal of sport nutrition and exercise metabolism. 2012,22:89-97.

[12] Tsai, M. L., Chou, K. M., Chang, C. K., Fang, S. H. Changes of mucosal immunity and antioxidation activity in elite male Taiwanese taekwondo athletes associated with intensive training and rapid weight loss. British journal of sports medicine. 2011,45:729-34.

[13] Braun, H., Koehler, K., Geyer, H., Kleiner, J., Mester, J., Schanzer, W. Dietary supplement use among elite young German athletes. Int J Sport Nutr Exerc Metab. 2009,19:97-109.

[14] Herbold, N. H., Visconti, B. K., Frates, S., Bandini, L. Traditional and nontraditional supplement use by collegiate female varsity athletes. Int J Sport Nutr Exerc Metab. 2004,14:586-93.

[15] Watt, J. Nutrition in adverse environments, 1. Forgotten lessons of maritime nutrition. Hum Nutr Appl Nutr. 1982,36:35-45.

[16] D’Archivio M, F. C., Di Benedetto R, Gargiulo R, Giovannini C, Masella R. Polyphenols, dietary sources and bioavailability. . Annali-Istituto Superiore di Sanita 2007.,38-61.

[17] Ferruzzi, M. G., Bordenave, N., Hamaker, B. R. Does flavor impact function? Potential consequences of polyphenol-protein interactions in delivery and bioactivity of flavan-3-ols from foods. Physiology \& behavior. 2012,107:591-7.

[18] Ferruzzi, M. G. The influence of beverage composition on delivery of phenolic compounds from coffee and tea. Physiology \& behavior. 2010,100:33-41.

[19] Zaki ME, E.-B. H., El-Gammal M, Kamal S. Indicators of the metabolic syndrome in obese adolescents. . Arch Med Sci. 2015. ,92-98.

[20] WHO. Obesity and overweight. Internet: http://www.who. int/mediacentre/factsheets/fs311/en/ (accessed 20 February 2017). 2016. 
[21] Smeriglio A, B. D., Bellocco E, Trombetta D. Chemistry, pharmacology and health benefits of anthocyanins. . Phytother Res 2016.,1265-1286.

[22] Yoshihara, D., Fujiwara, N., Suzuki, K. Antioxidants: benefits and risks for long-term health. Maturitas. 2010,67:103-7.

[23] Ghosh, D., Scheepens, A. Vascular action of polyphenols. Mol Nutr Food Res. 2009,53:322 -31.

[24] Gonzalez, R., Ballester, I., Lopez-Posadas, R., Suarez, M. D., Zarzuelo, A., Martinez-Augustin, O., et al. Effects of flavonoids and other polyphenols on inflammation. Crit Rev Food Sci Nutr. 2011,51:331-62.

[25] Doha Mohamed A., H. I. M., Al-Okbi Sahar Y.,. Ceratonia siliqua Pods as a Cheap Source of Functional Food Components, . Deutsche Lebensmittel-Rundschau, Vol. 104, N¹, . (2008), :pp. 25-9.

[26] Kumazawa, S., Taniguchi, M., Suzuki, Y., Shimura, M., Kwon, M. S., Nakayama, T. Antioxidant activity of polyphenols in carob pods. J Agric Food Chem. 2002,50:373-7.

[27] Hichem S, A. S., Latifa C, Kais R, Mohamed A, Jamel EB, et al. In vitro and in vivo antioxidant properties of Tunisian carob (Ceratonia siliqua L.). . J Med Food Res. . 2013;: 85-90. .

[28] Papagiannopoulos, M., Wollseifen, H. R., Mellenthin, A., Haber, B., Galensa, R. Identification and quantification of polyphenols in carob fruits (Ceratonia siliqua L.) and derived products by HPLC-UV-ESI/MSn. J Agric Food Chem. 2004,52:3784-91.

[29] Hsouna, A. B., Trigui, M., Mansour, R. B., Jarraya, R. M., Damak, M., Jaoua, S. Chemical composition, cytotoxicity effect and antimicrobial activity of Ceratonia siliqua essential oil with preservative effects against Listeria inoculated in minced beef meat. Int J Food Microbiol. 2011,148:66-72.

[30] Souli A, S. H., Chehimi L, Rtibi K, Tounsi H, Boubaker S, Sakly M, El-Benna J, Amri M: doi:10.1177/0748713475506. Hepatoprotective effect of carob against acute ethanol-induced oxidative stress in rat. Toxicol. Ind. health. 2013.

[31] Pieter W, H. J. Training and competition in taekwondo. J Asian Martial Arts. . 2003;:8-22.

[32] Campos, F. A., Bertuzzi, R., Dourado, A. C., Santos, V. G., Franchini, E. Energy demands in taekwondo athletes during combat simulation. European journal of applied physiology. 2012,112:1221-8.

[33] Tornello, F., Capranica, L., Chiodo, S., Minganti, C., Tessitore, A. Time-motion analysis of youth Olympic Taekwondo combats. Journal of strength and conditioning research. 2013,27:223-8.

[34] Bridge, C. A., McNaughton, L. R., Close, G. L., Drust, B. Taekwondo exercise protocols do not recreate the physiological responses of championship combat. International journal of sports medicine. 2013,34:573-81.

[35] Capranica, L., Lupo, C., Cortis, C., Chiodo, S., Cibelli, G., Tessitore, A. Salivary cortisol and alpha -amylase reactivity to taekwondo competition in children. European journal of applied physiology. 2012,112:647-52.

[36] Monoem Haddad 1, A. C., Del P. Wong 2, Carlo Castagna 3, 1, K. C. Heart Rate Responses and Training Load During Nonspecific and Specific Aerobic Training in Adolescent Taekwondo Athletes Journal of Human Kinetics volume. 2011,59-66

[37] Falco, C., Alvarez, O, Castillo, I, et al. Influence of the distance in a roundhouse kick's execution time and impact force in Taekwondo.. ;. J Biomech. 2009,242-248.

[38] Durnin, J. V., Womersley, J. Body fat assessed from total body density and its estimation from skinfold thickness: measurements on 481 men and women aged from 16 to 72 years. Br J Nutr. 1974,32:77-97.

[39] Krustrup, P., Mohr, M., Amstrup, T., Rysgaard, T., Johansen, J., Steensberg, A., et al. The yo-yo intermittent recovery test: Physiological response, reliability, and validity. Medicine and science in sports and exercise. 2003,35: 697-705.

[40] Foster, C., Florhaug, JA, Franklin, J, et al. . A new approach to monitoring exercise training. . J Strength Cond

Res. 2001;,109-115.

[41] Yu Z, D. R. A. Evaluation of methods for measuring polyphenols in copper foliage, pp. J.Chem.Ecol.:.211940. 
[42] Catalano L, F. I., De Nobili M, Leita L., , . Polyphenols in olive mill waste waters and their depuration plant effluents: a comparison of the Folin-Ciocalteau and HPLC methods, . Agrochimica N43,. (1999): pp. 193-205.

[43] Dogyan S., T. Y., Ertuerk H., Arslan D. Characterization and Purification of polyphenol oxydase from artichoke (Cynara scolymus L.), . J.Agric.Food Chem., . (2005),776-785.

[44] georgakouli, K., Mpesios, A, Kouretas, D, Petrotos, K, Mitsagga, C, Giavasis, I et Jamurtas,A.Z. The effects of an olive fruit polyphenol-enriched yoghurt on body composition, blood redox status, physiological and metabolic parameters and yogurt microflora. nutrients. 2016,344.

[45] Wu, T., Guo, Y., Liu, R., Wang, K., Zhang, M. Black tea polyphenols and polysaccharides improve body composition, increase fecal fatty acid, and regulate fat metabolism in high-fat diet-induced obese rats. Food Funct. 2016,7:2469-78.

[46] Amiot, M., Riva, C. \& Vinet, A. 2016. Effects Of Dietary Polyphenols On Metabolic Syndrome Features In Humans: . Obesity Reviews, A Systematic Review., 573-586.

[47] Romain, C., Alcaraz, P. E., Chung, L. H., Cases, J. Regular consumption of HolisFiit, a polyphenol-rich extractbased food supplement, improves mind and body well-being of overweight and slightly obese volunteers: a randomized, double-blind, parallel trial. Int J Food Sci Nutr. 2017,68:840-8.

[48] Benaraba, R. Insulinorésistance Et Stress Oxydant Dans Le Syndrome Métabolique: Etude Expérimentale Des Effets Protecteurs De Microconstituants Nutritionnels (Polyphénols Du Thé, De La Cannelle Et Chrome lii). Université Joseph-Fourier-Grenoble I. 2007.

[49] Farhat, G., Drummond, S., Al - Dujaili, E. A. Polyphenols and Their Role in Obesity Management: A Systematic Review of Randomized Clinical Trials. Phytotherapy Research. 2017.

[50] Poulsen, M. M., Vestergaard, P. F., Clasen, B. F., Radko, Y., Christensen, L. P., Stodkilde-Jorgensen, H., et al. High-dose resveratrol supplementation in obese men: an investigator-initiated, randomized, placebocontrolled clinical trial of substrate metabolism, insulin sensitivity, and body composition. Diabetes. 2013,62:1186-95.

[51] Di Renzo L, Rizzo M, Sarlo F, et al. effects of dark chocolate in a population of normal weight obese women : a pilot study Eur Rev med pharmacol sci. 2013,2257-2266.

[52] Pfeuffer M, A. A., Bley $U$, et al. effect of quercetin on traits of the metabolic syndrome, endothelial function and inflammation in men with different APOE isoforms. Nutr metab cardiovas 2013,403-409.

[53] Hughes LA, A. I., Ambergen T, et al. 2008. Higher dietary flavone, flavonol, and catechin intakes are associated with less of an increase in BMI over time in women: a longitudinal

analysis from the Netherlands cohort study. . Am J Clin Nutr.1341-1352.

[54] Golomb, B. A., Koperski, S., White, H. L. Association between more frequent chocolate consumption and lower body mass index. Arch Intern Med. 2012,172:519-21.

[55] Meydani, M., Hasan, S. T. Dietary polyphenols and obesity. Nutrients. 2010,2:737-51.

[56] Farhat, G., Drummond, S., Al-Dujaili, E. A. S. Polyphenols and Their Role in Obesity Management: A Systematic Review of Randomized Clinical Trials. Phytother Res. 2017,31:1005-18.

[57] Natsume, M., Osakabe, N., Oyama, M., Sasaki, M., Baba, S., Nakamura, Y., et al. Structures of (-)epicatechin glucuronide identified from plasma and urine after oral ingestion of (-)-epicatechin: differences between human and rat. Free Radic Biol Med. 2003,34:840-9.

[58] Leibel, R. L. Molecular physiology of weight regulation in mice and humans. Int J Obes (Lond). 2008,32 Suppl 7:S98-108.

[59] Etcheverry, P., Grusak, M. A., Fleige, L. E. Application of in vitro bioaccessibility and bioavailability methods for calcium, carotenoids, folate, iron, magnesium, polyphenols, zinc, and vitamins $B(6), B(12)$, D, and E. Front Physiol. 2012,3:317.

[60] Min SY, Y. H., Seo SG, et al. 2013. Cocoa polyphenols suppress adipogenesis in vitro and obesity in vivo by targeting insulin receptor. . Int J Obesity.584-592.

[61] Ejaz, A., Wu, D., Kwan, P., Meydani, M. Curcumin inhibits adipogenesis in 3T3-L1 adipocytes and angiogenesis and obesity in C57/BL mice. J Nutr. 2009,139:919-25. 
[62] Davis JM, C. C., Chen S, Carmichael MD, Murphy EA. .The Dietary Flavonoid Quercetin Increases VO2max and Endurance Capacity.. Int J Sport Nutr Exerc Metab. 2010;,56-62.

[63] Dolinsky VW, J. K., Sidhu RS, Haykowsky M, Czubryt MP, Gordon T and Dyck JR. Improvements in skel etal muscle strength and cardiac function induced by resviratol contribute to enhanced exercise performance in rats. J physiol 2012:2783-99.

[64] Hart N, S. L., Csende Z, Koltai E, Koch LG, Britton SL, Davies KJ, Kouretas D, Wessner B and Radak Z:. Resveratrol enhances exercise training responses in rats selectively bred for high running performance. . Food Chem Toxicol 2013,53 59.

[65] Casuso, R. A., Martinez-Amat, A., Martinez-Lopez, E. J., Camiletti-Moiron, D., Porres, J. M., Aranda, P. Ergogenic effects of quercetin supplementation in trained rats. J Int Soc Sports Nutr. 2013,10:3.

[66] Hart, N., Sarga, L., Csende, Z., Koch, L. G., Britton, S. L., Davies, K. J., et al. Resveratrol attenuates exerciseinduced adaptive responses in rats selectively bred for low running performance. Dose Response. 2014,12:57 71.

[67] Scribbans, T. D., Ma, J. K., Edgett, B. A., Vorobej, K. A., Mitchell, A. S., Zelt, J. G., et al. Resveratrol supplementation does not augment performance adaptations or fibre-type-specific responses to high-intensity interval training in humans. Appl Physiol Nutr Metab. 2014,39:1305-13.

[68] Voduc, N., Ia Porte, C., Tessier, C., Mallick, R., Cameron, D. W. Effect of resveratrol on exercise capacity: a randomized placebo-controlled crossover pilot study. Appl Physiol Nutr Metab. 2014,39:1183-7.

[69] Labonte' K, C. C., Motard-Be'langer A, et al. . Acute effects of polyphenols from cranberries and grape seeds on endothelial function and performance in elite athletes. . Sports. 2013;1:55-68. 
Table 1. The TKD training program performed each week during six-weeks.

Structure of 4 training sessions performed each week

\begin{tabular}{|c|c|c|c|}
\hline Session 1 (IT) & Session 2 (TT) & Session 3 (TD) & Session 4 (Randori) \\
\hline $\begin{array}{l}-15 \text { min warm up } \\
\text {-Specific technical } \\
\text { interval training ( } 4 \\
\text { bouts of exercise } \\
\text { lasting for } 4 \text { min with } 4 \\
\text { min of active recovery } \\
\text { in-between. Each bout } \\
\text { consisted of short } \\
\text { duration high intensity } \\
\text { interval exercise (i.e. } \\
\text { 10: } 20 \text { [10 s of exercise } \\
\text { interspersed with } 20 \mathrm{~s} \\
\text { of passive recovery]) } \\
-10 \text { min stretching }\end{array}$ & $\begin{array}{l}-15 \text { min warm up } \\
-45 \text { min of various } \\
\text { TKD techniques } \\
\text { (offensive and } \\
\text { defensive } \\
\text { situations) } \\
\text {-10min of free } \\
\text { Taekwondo } \\
\text { sparring. } \\
\text {-10min stretching }\end{array}$ & $\begin{array}{l}-15 \text { min warm up } \\
- \text { Technical } \\
\text { Kirougui repetitions } \\
(8 \times 3 \text { min; } 1 \text { min30 } \\
\text { rest between) } \\
-10 \text { min stretching }\end{array}$ & $\begin{array}{l}\text {-Individual } 15 \mathrm{~min} \\
\text { warm up } \\
\text {-Free TKD sparring ( } 7 \\
\text { x } 2 \text { min; 1min rest } \\
\text { between) } \\
\text {-10 min stretching }\end{array}$ \\
\hline
\end{tabular}

Table 2: Effects of carob supplementation on body composition.

\begin{tabular}{|c|c|c|c|c|c|c|c|c|}
\hline \multirow[b]{2}{*}{ Measure } & \multirow[b]{2}{*}{ Grou } & \multirow[b]{2}{*}{ Pre-test } & \multirow[b]{2}{*}{ Post-test } & \multirow[b]{2}{*}{$\begin{array}{l}\text { Chang } \\
\text { e }(\%)\end{array}$} & \multirow[b]{2}{*}{$\begin{array}{l}\text { Cohen' } \\
\text { s d }\end{array}$} & \multicolumn{3}{|c|}{ Differences } \\
\hline & & & & & & $\mathbf{F}$ & $\begin{array}{l}\mathbf{P} \\
\text { valu }\end{array}$ & $\eta p 2$ \\
\hline \multirow{2}{*}{$\begin{array}{l}\text { Weight } \\
\text { (Kg) }\end{array}$} & SG & $\begin{array}{l}70.77 \pm 12.6 \\
3\end{array}$ & $\begin{array}{l}68.8 \pm 12.41 * * \\
*\end{array}$ & $-2.82 \%$ & 0.16 & \multirow{2}{*}{$\begin{array}{l}23.17 \\
9\end{array}$} & \multirow{2}{*}{$\begin{array}{l}0.00 \\
0\end{array}$} & \multirow{2}{*}{$\begin{array}{l}0.53 \\
7\end{array}$} \\
\hline & PG & $\begin{array}{l}68.40 \pm 15.9 \\
6\end{array}$ & $67.63 \pm 15.83^{*}$ & $-0.51 \%$ & 0.02 & & & \\
\hline BMI & SG & $24.53 \pm 5.28$ & $\begin{array}{l}23.75 \pm 5.13 * * \\
*\end{array}$ & $-3.16 \%$ & 0.15 & $\begin{array}{l}32.59 \\
1\end{array}$ & $\begin{array}{l}0.00 \\
0\end{array}$ & $\begin{array}{l}0.62 \\
0\end{array}$ \\
\hline
\end{tabular}




\begin{tabular}{|c|c|c|c|c|c|c|c|c|}
\hline & PG & $23.45 \pm 4.29$ & $23.33 \pm 4.29$ & $-0.50 \%$ & 0.03 & & & \\
\hline \multirow{2}{*}{$\% \mathrm{BF}$} & $\mathrm{SG}$ & $\begin{array}{l}20,14 \\
\pm 8.61\end{array}$ & $19.08 \pm 9.19 *$ & $-7.40 \%$ & 0.12 & \multirow{2}{*}{3.015} & \multirow{2}{*}{$\begin{array}{l}0.09 \\
8\end{array}$} & \multirow{2}{*}{$\begin{array}{l}0.13 \\
1\end{array}$} \\
\hline & PG & $20.73 \pm 7.27$ & $21.20 \pm 8.86$ & $\begin{array}{l}+0.31 \\
\%\end{array}$ & 0.06 & & & \\
\hline \multirow{2}{*}{ MV } & $\mathrm{SG}$ & $3.30 \pm 0.93$ & $3.59 \pm 1.23$ & $\begin{array}{l}+8.49 \\
\%\end{array}$ & 0.32 & \multirow{2}{*}{1.29} & \multirow{2}{*}{$\begin{array}{l}0.26 \\
9\end{array}$} & \multirow{2}{*}{$\begin{array}{l}0.06 \\
1\end{array}$} \\
\hline & PG & $3.29 \pm 0.79$ & $3.24 \pm 1.18$ & $-2.30 \%$ & 0. & & & \\
\hline
\end{tabular}

$\mathrm{BMI}=$ body mass index; $\mathrm{BF}=$ body fat; $\mathrm{MV}=$ muscular volume; $* \mathrm{p} \leq 0.05 ; * * \mathrm{p} \leq 0.01 ; * * *$ $\mathrm{p} \leq 0.001$.

Table 3: Effects of carob supplementation on aerobic performance, rating of perceived exertion and heart rate after yo-yo intermittent recovery test.

\begin{tabular}{|c|c|c|c|c|c|c|c|c|}
\hline \multirow[b]{2}{*}{ Variable } & \multirow[b]{2}{*}{$\begin{array}{l}\text { Grou } \\
\text { p }\end{array}$} & \multirow[b]{2}{*}{ Pre-test } & \multirow[b]{2}{*}{ Post-test } & \multirow[b]{2}{*}{$\begin{array}{l}\text { Chang } \\
\text { e (\%) }\end{array}$} & \multirow[b]{2}{*}{$\begin{array}{c}\text { Cohen' } \\
\text { s d }\end{array}$} & \multicolumn{3}{|c|}{ Differences } \\
\hline & & & & & & $\mathbf{F}$ & $\begin{array}{l}\mathbf{P} \\
\text { valu }\end{array}$ & пр2 \\
\hline \multirow{2}{*}{$\begin{array}{l}\text { Distance } \\
\text { (m) }\end{array}$} & SG & $\begin{array}{l}847.2 \pm 473 \\
.9\end{array}$ & $\begin{array}{l}1494.9 \pm 619.2 * \\
* *\end{array}$ & $\begin{array}{c}92.43 \\
\%\end{array}$ & 1.37 & \multirow{2}{*}{$\begin{array}{l}14.04 \\
2\end{array}$} & \multirow{2}{*}{$\begin{array}{l}0.00 \\
1\end{array}$} & \multirow{2}{*}{$\begin{array}{l}0.41 \\
2\end{array}$} \\
\hline & PG & $\begin{array}{l}786.6 \pm 438 \\
.3\end{array}$ & $\begin{array}{l}1046.6 \pm 543.6^{*} \\
*\end{array}$ & $\begin{array}{c}40.37 \\
\%\end{array}$ & 0.59 & & & \\
\hline \multirow{2}{*}{$\begin{array}{l}\text { MAV } \\
(\mathbf{K m} / \mathbf{h})\end{array}$} & $\mathrm{SG}$ & $13.7 \pm 1.2$ & $15.5 \pm 1.6 * * *$ & $\begin{array}{c}12.18 \\
\%\end{array}$ & 1.35 & \multirow{2}{*}{$\begin{array}{l}13.55 \\
2\end{array}$} & \multirow{2}{*}{$\begin{array}{l}0.00 \\
1\end{array}$} & \multirow{2}{*}{$\begin{array}{l}0.40 \\
4\end{array}$} \\
\hline & $\mathrm{PG}$ & $13.6 \pm 1.2$ & $14.3 \pm 1.5^{* *}$ & $4.95 \%$ & 0,60 & & & \\
\hline \multirow{2}{*}{$\begin{array}{l}\text { HR } \\
\text { (beat/min) }\end{array}$} & SG & $\begin{array}{l}185.4 \pm 10 . \\
5\end{array}$ & $182.9 \pm 6.9$ & $-1.15 \%$ & 0.23 & \multirow{2}{*}{1.118} & \multirow{2}{*}{$\begin{array}{l}0.30 \\
3\end{array}$} & \multirow{2}{*}{$\begin{array}{l}0.05 \\
3\end{array}$} \\
\hline & PG & $185.3 \pm 9.8$ & $184.9 \pm 8.6$ & $-0.15 \%$ & 0.03 & & & \\
\hline RPE (AU) & SG & $7.9 \pm 0.7$ & $8.4 \pm 0.5^{* * *}$ & $6.33 \%$ & 0.65 & 18.09 & 0.00 & 0.47 \\
\hline
\end{tabular}




\begin{tabular}{|l|l|l|l|l|l|l|l|l|}
\hline & PG & $7.3 \pm 0.8$ & $7.2 \pm 0.6$ & $-0.40 \%$ & 0.11 & 6 & 0 & 5 \\
\hline
\end{tabular}

$\mathrm{MAV}=$ maximal aerobic velocity; $\mathrm{HR}=$ heart rate; $\mathrm{RPE}$ : rating of perceived exertion; $\mathrm{AU}$ : Arbitrary units.

$* \mathrm{p} \leq 0.05 ; * * \mathrm{p} \leq 0.01 ; * * * \mathrm{p} \leq 0.001$ 